\title{
O papel do erro na formação do "espírito científico" de licenciandos de Ciências Naturais a partir da Aprendizagem Baseada em Projetos
}

\author{
The role of error in the formation of the "scientific spirit" of students in \\ Natural Sciences based on Project-Based Learning
}

\section{El papel del error en la formación del "espíritu científico" de los estudiantes de Ciencias Naturales a partir del Aprendizaje Basado en Proyectos}

\author{
Jéssica Mirian Sampaio Laves (jessicamirian@ufam.edu.br) \\ Universidade Federal do Amazonas. \\ Ettore Paredes Antunes (ettore@ufam.edu.br) \\ Universidade Federal do Amazonas.
}

\begin{abstract}
Resumo: Fundamentado no referencial teórico de Gaston Bachelard, com recorte em suas ideias sobre o erro e o espírito científico, o presente artigo analisa de que forma a Aprendizagem Baseada em Projetos (ABP) contribui para o desenvolvimento do espírito científico na formação inicial de professores de Ciências Naturais, a partir do papel do erro no processo. O estudo utiliza a abordagem metodológica qualitativa do tipo exploratória, através da observação participante. Foi realizado em uma turma do curso de Ciências Naturais de uma Universidade Pública Federal localizada na região Norte, durante uma disciplina do curso. Para a análise das respostas obtidas por entrevistas e grupo focal, foi utilizada a Análise Textual Discursiva. Foi evidenciado que o desenvolvimento da questão problema do projeto mostrou-se como característica definidora da referida metodologia ativa que incita o desenvolvimento do espírito científico. No entanto, o resultado central evidenciado foi o medo de errar, exposto por, aproximadamente, $40 \%$ dos discentes, o que enveredou para a discussão de como este medo pode comprometer o desenvolvimento do espírito científico na formação do professor. Em última análise, a ABP mostrou-se como "experiência exigente" no viés de Bachelard. Desta maneira, a metodologia promoveu ponderações sobre como futuros professores concebem o erro e como este orienta suas ações, convergindo em discussões sobre o processo de desenvolvimento do espírito científico.
\end{abstract}

Palavras-chave: ABP; Formação docente; Desenvolvimento do espírito científico; O medo de errar; Educação em Ciências e Matemática.

Abstract: Based on the theoretical framework of Gaston Bachelard, with a focus on his ideas about error and the scientific spirit, this article analyzes how Project-Based Learning contributes to the development of the scientific spirit in the initial training of Natural Science teachers, from the role of error in the process. The study uses a qualitative exploratory methodological approach, through participant observation. It was carried out in a class of the 
Natural Sciences course at a Federal Public University located in the North region, during a course subject. For the analysis of the responses obtained through interviews and focus groups, Discursive Textual Analysis was used. It was evidenced that the development of the project's problem question was shown as a defining characteristic of the referred active methodology that encourages the development of the scientific spirit. However, the main result evidenced was the fear of making mistakes, exposed by approximately $40 \%$ of the students, which led to the discussion of how this fear can compromise the development of the scientific spirit in teacher education. Ultimately, PBL proved to be a "demanding experience" in Bachelard's bias. In this way, the methodology promoted considerations about how future teachers conceive the error and how it guides their actions, converging on discussions about the process of development of the scientific spirit.

Keywords: ABP; Teacher training; Development of the scientific spirit; The fear of making mistakes; Science and Mathematics Education

Resumen: Partiendo del marco teórico de Gaston Bachelard, con un enfoque en sus ideas sobre el error y el espíritu científico, este artículo analiza cómo el Aprendizaje Basado en Proyectos contribuye al desarrollo del espíritu científico en la formación inicial de los docentes de Ciencias Naturales, desde el rol de error en el proceso. El estudio utiliza un enfoque metodológico exploratorio cualitativo, a través de la observación participante. Se llevó a cabo en una clase del curso de Ciencias Naturales en una Universidad Pública Federal ubicada en la región Norte, durante una asignatura del curso. Para el análisis de las respuestas obtenidas a través de entrevistas y grupos focales se utilizó Análisis Textual Discursivo. Se evidenció que el desarrollo de la pregunta problemática del proyecto se mostró como una característica definitoria de la referida metodología activa que incentiva el desarrollo del espíritu científico. Sin embargo, el principal resultado evidenciado fue el miedo a cometer errores, expuesto por aproximadamente el $40 \%$ de los estudiantes, lo que llevó a la discusión de cómo este miedo puede comprometer el desarrollo del espíritu científico en la formación del profesorado. Al final, PBL demostró ser una "experiencia exigente" en el sesgo de Bachelard. De esta manera, la metodología promovió consideraciones sobre cómo los futuros docentes conciben el error y cómo este orienta sus acciones, convergiendo en discusiones sobre el proceso de desarrollo del espíritu científico.

Palabras-clave:ABP; Formación de profesores; Desarrollo del espíritu científico; El miedo a cometer errores; Educación en Ciencias y Matemáticas.

\section{INTRODUÇÃO}

As considerações iniciais do presente estudo recaem sobre o epistemólogo francês, Gaston Bachelard, que aborda em sua teoria o objetivo de despertar o raciocínio e o questionamento. Logo, enfatiza que a via psicológica do pensamento científico percorre a seguinte lógica: “sobre qualquer questão, sobre qualquer fenômeno, é preciso passar primeiro 
da imagem para a forma geométrica e, depois, da forma geométrica para a forma abstrata" (BACHELARD, 1996, p. 11).

O progresso do espírito científico pode começar com uma simples observação dos fenômenos ligados ao conhecimento imediato, passando para um estado intermediário, concreto-abstrato, para finalmente chegar ao estado abstrato. $\mathrm{O}$ desenvolvimento do espírito científico está ligado ao saber questionar. Assim, Bachelard estabelece a seguinte discussão: O espírito científico proíbe que tenhamos uma opinião sobre questões que não compreendemos, sobre questões que não sabemos formular com clareza. Em primeiro lugar, é preciso saber formular problemas (BACHELARD, 1996, p. 18).

Acrescenta-se, ainda, à luz de Japiassu (1976) que a epistemologia de Bachelard evidencia a descontinuidade, seu pensamento se baseia na importância da retificação do erro:

Não é contemplando, mas construindo, criando, produzindo e retificando que o espírito chega à verdade. $\mathrm{O}$ conhecimento científico torna-se operativo: é uma operação. A ciência cria seus próprios objetos pela destruição dos objetos de percepção comum, dos conhecimentos imediatos (JAPIASSU, 1976, p. 26).

Vale acentuar que o erro, na visão de Gaston Bachelard, assume função positiva na gênese do conhecimento (LOPES, 1996). Diferencia-se do erro visto na pedagogia tradicional como falha que precisa ser evitada. Para o epistemólogo francês, o erro torna-se um elemento fundamental para a prática científica, pois a partir dele podemos questionar e dialogar para compreender as questões e os fenômenos que se apresentam no ensino e na aprendizagem.

Dentro deste contexto, na pedagogia científica de Bachelard "o erro se instrui a partir de uma dinâmica pedagógica que coloque o conhecimento em permanente estado de crise, criando sempre a necessidade de retificar-se" (FONSECA, 2008, p. 366). Assim, o conhecimento estará em constante retificação e o sujeito diante do erro não irá desconsiderálo, como se fosse algo negativo e desprovido de conhecimento; pelo contrário, seu entendimento estará sempre em função de gerar conhecimento. Consoante, Barbosa e Bulcão (2004) a dialética entre o conhecimento novo e anterior deve ser frequentemente praticada para que haja desenvolvimento do espírito científico.

A presente discussão ganha notório relevo quando articulamos as ideias supracitadas com a Aprendizagem Baseada em Projetos, doravante ABP. Para este estudo, dialogamos com o educador norte-americano William Bender, que apresenta o seguinte conceito para ABP:

A ABP é uma técnica de ensino baseada por pesquisas com o objetivo de promover o desenvolvimento de projetos, baseados em uma questão, tarefa ou problema, para 
ensinar conteúdos acadêmicos aos alunos no contexto do trabalho cooperativo para a resolução de problemas (BENDER, 2015, p. 15).

Na ABP o aluno coloca-se em desafio para responder a uma tarefa, resolver um problema ou criar uma questão-problema, ou seja, é possível duvidar, criticar e desenvolver questões e não reproduzi-las. Frente ao exposto, a epistemologia bachelardiana é essencial para aprofundar e dialogar diante do erro e desenvolvimento do espírito científico e abre oportunidades para se repensar sobre as características da referida metodologia ativa na formação inicial de professores de Ciências.

A formação inicial do professor tem por objetivo a preparação cujas habilidades estejam de acordo com a necessidade da sociedade (SANTOS DE SOUZA et al., 2020). Neste sentido, a ABP é estimulante para os discentes em processo de formação de professores de Ciências, pois os deixam no centro da aprendizagem, colocando-os como protagonistas do processo fazendo-os refletir sobre os problemas da sociedade e dando-lhes o controle sobre o quê fazer, como resolver e aplicar o conhecimento proporcionando a aprendizagem significativa (BENDER,2015). Sobre a aprendizagem significativa na formação inicial de professores de Ciências Suárez Silva et al. (2018) esclarecem:

A aprendizagem de forma significativa pelos estudantes, deve ser um objetivo a ser
alcançado pelos professores dentro do processo de ensino - aprendizagem, sendo
uma alternativa para mudar metodologias tradicionais para metodologias
construtivistas, com a finalidade de que o conhecimento deixe de ser mecânico e
passe a ter um significado para o estudante (SUÁREZ SILVA et al. $(2018$, p.3).

Por conseguinte, o objetivo do artigo foi analisar de que forma a ABP contribui para o desenvolvimento do espírito científico na formação inicial de professores de Ciências Naturais, a partir do papel do erro no processo.

\section{DAS IDEIAS IRREFLETIDAS DO ERRO NO ENSINO TRADICIONAL ÀS PERSPECTIVAS POSITIVAS PARA O DESENVOLVIMENTO DO CONHECIMENTO}

A princípio, na pedagogia tradicional o discente é sujeito passivo de acúmulo de informações transferidas pelo professor, caracterizando-se como uma educação bancária (FREIRE, 2007). A par disso, práticas inflexíveis nas quais o aluno não participa, e somente ouve sem contribuir ativamente, são antiquadas diante das obrigações exigidas 
hodiernamente. $\mathrm{O}$ erro, por exemplo, ainda é visto como algo que precisa ser evitado e em algumas situações é até mesmo penalizado, visto que o modelo de avaliação de provas e a exigência de notas ainda vigoram (DAMASCENO JUNIOR, 2020).

Todavia, as punições advindas dos erros carregam uma perspectiva histórica, como podemos observar no seguinte estudo:

Nos anos 1800, os castigos físicos tinham dois fins: punir o mau comportamento e a dificuldade de aprendizagem. Férulas, chicotes e palmatórias faziam parte dos objetos utilizados pelo professor para educar os alunos, mantendo a ordem e a disciplina (ARAGÃ̃, 2012, p. 18).

Com o passar do tempo, práticas punitivas em alguns estados brasileiros, como na Paraíba e no Mato Grosso, foram até regulamentadas por leis que estipulavam como as penalidades físicas deveriam acontecer, levando em conta a idade do aluno e a gravidade da ação realizada (ARAGÃO, 2012).

Neste ínterim, nossas observações recaem sobre a ressignificação do erro, logo destacamos as considerações de Lopes (1996) sobre Bachelard:

O erro deixa de ser interpretado como um equívoco, ou seja, o erro assume uma função positiva na gênese do saber e a própria questão da verdade se modifica. Não podemos mais nos referir à verdade, mas às verdades múltiplas, históricas. As verdades só adquirem sentido ao fim de uma polêmica, após a retificação dos erros primeiros (LOPES, 1996, p. 252).

À luz do artigo de Souza et al. (2013) a ressignificação dos erros no processo de ensino e na aprendizagem também é discutido:

Os erros não precisam ser combatidos, mas podem ser ressignificados no contexto da sala de aula; compreendidos, podem ser superados. Percebidos em seu valor informacional, podem balizar intervenções pedagógicas adequadas e oportunas, intentando sua superação. Ao não se configurarem entraves, podem ser reconhecidos como propulsores da ação. Erros não precisam e não devem estar associados à ideia de fracasso e incompetência, de desistência e estagnação (SOUZA et al.; 2013, p. 3).

Ademais, percebe-se na obra de Bachelard algo preciso que denominamos o "erro Bachelardiano", ou seja, o erro positivo no qual o conhecimento é colocado em permanente diálogo e contestação, sempre a favor do conhecimento e do espírito científico. Desta forma, não é algo que denota falha do espírito científico, mas a oportunidade de retificar o pensamento, logo o erro e a retificação fazem parte da prática e da pedagogia científica. 
Para enfatizar a perspectiva positiva de erro proposta por Bachelard, citamos o seguinte questionamento realizado em sua obra "Formação do Espírito Científico" (1996, p14): [...] "a experiência que não retifica nenhum erro, que é monotonamente verdadeira, sem discussão, para que serve? ". Logo, a partir desse questionamento é notório o engajamento a favor das discussões relevantes diante do erro. Destaca-se que Gaston Bachelard ao propor que "a primeira experiência é a experiência que falha" (1996, p. 296) denota o papel do erro no progresso da Ciência.

Vale acentuar que vários pesquisadores têm concluído estudos que abordam a relevância do erro nas áreas de ensino de Ciências e Matemática, Biologia, Química e Neurociência, dentre eles, no ensino de química, Carrijo e Mendes (2017, p. 132) discutem "O desenvolvimento da inteligência e do conhecimento científico tem como principal referência à regulação oriunda de uma situação perturbadora, que muitas vezes se relaciona com o erro".

A maneira como o ensino de ciência e química é desenvolvido pode promover a visão equivocada de ciência nos alunos, logo o papel do erro na desconstrução dessas visões inadequadas é relevante (ZYTKUEWISZ E BEGO, 2018).

Santos Júnior e Barboza (2020) discutem sobre a importância de compreender as causas e as motivações do erro dos alunos:

A construção de uma prática pedagógica atenta ao que acontece na sala de aula em seus diversos detalhes, continua sendo um desafio posto aos educadores. Compreender causas e motivações do erro do aluno constitui-se num dos pilares que pode ajudar a melhorar o processo de ensinar do professor e a aprendizagem do aluno (SANTOS JÚNIOR;BARBOZA, 2020, p. 14).

No trabalho de Damasceno Júnior (2020) foi discutido que compreender a aprendizagem é perceber o erro, sua origem e desenvolvimento e a compreensão dos aspectos neurocientíficos pode proporcionar uma melhor atuação pedagógica, assim o docente poderá abordar o estudo da Ciência e Matemática com ferramentas mais adequadas. Do mesmo modo, Miranda et al.(2018) relatam que os erros são fontes de conhecimento, a saber:

As pesquisas sobre os erros dos alunos produzidas ao longo dos anos, tanto no âmbito geral quanto especificamente em cada área de conhecimento disciplinar, nos permitem não apenas considerá-lo como ferramenta da ação pedagógica, mas nos alertam para as muitas fontes de sua existência e ao mesmo tempo em que buscam contribuir com nosso fazer profissional, aumenta consideravelmente nossa responsabilidade; visto que ao nos tornar cientes destas possíveis causas de erros e suas subjacências, nos impõe a necessidade de saber reconhecê-las e nortear nossa ação para contribuir com os alunos na perspectiva de sua superação a fim de que o

Recebido em: 25/11/2020

Aceite em: 28/07/2021 
objetivo do processo educativo seja alcançado - a aprendizagem (MIRANDA et al., 2018, p. 39).

Sob esse prisma, Pessim e Leite (2020) abordam que um dos temas que precisam de maior discussão na formação inicial e na formação continuada do professor de matemática é o conhecimento sobre a avaliação do processo de ensino e aprendizagem no tocante a avaliação, assim destaca-se o erro no processo, que se constitui, como uma temática pouco investigada. Segundo os autores compreender o erro é fundamental no processo de formação do professor, dado que esse deverá identificar o erro dos alunos, além de saber diferenciar os tipos e intervir para que ocorra a aprendizagem.

No trabalho de Brito et al. (2020. p. 182) destacam-se as contribuições de Bachelard para orientar a formação docente em Ciências e Matemática referente a avaliação: “Gaston Bachelard, não trata em específico de avaliação, mas contribui para se pensar a produção do conhecimento numa perspectiva histórica, que, por conseguinte, poderá auxiliar os professores na compreensão do conhecimento". Esses autores trazem questões essenciais sobre a percepção do erro em avaliações, além da importância do erro no processo de ensino e aprendizagem, por outro lado delineia-se oportuno lembrar que não foram identificados trabalhos que estabeleçam a relação direta entre a metodologia ativa, ABP e a epistemologia bachelardiana atrelada ao erro na formação do professor de ciências naturais, constante no presente trabalho.

\section{CONSIDERAÇÕES SOBRE A APRENDIZAGEM BASEADA EM PROJETOS} (ABP)

A ABP permite aos alunos pensarem problematizando questões que considerem significativas, instigando-os ao trabalho em equipe, estimulando a colaboração. Essa metodologia é fundamental para os discentes em processo de formação, pois deixa-os no centro da aprendizagem, colocando-os como protagonistas do processo (BENDER, 2015). O objetivo da $\mathrm{ABP}$ é que o grupo seja capaz de criar um possível projeto para construir, investigar ou explicar um problema (ANTUNES et al., 2019).

É importante destacar o papel do professor em sala de aula, que passa a ser um mediador do processo, guiando e auxiliando os alunos durante a aprendizagem. Em suma, o estudante tem voz mais ativa na escolha, execução e apresentação dos trabalhos (BENDER, 
2015). Na ABP trabalha-se a capacidade dos alunos pensarem, mediante o "aprender a fazer" envolvendo-os na obtenção de informações e competências através da busca da resolução de problemas, autênticos, planejados para uma aprendizagem dinâmica (LOVATO et al., 2018).

A ABP foi utilizada no trabalho de Garcês et al. (2018) como estratégia no ensino da disciplina de graduação Bioquímica Metabólica, em um curso de Licenciatura em Ciências da Natureza. No estudo de Siqueira e Goi (2020) foi destacado a relevância do desenvolvimento de curso de formação aliado a alternativas de ensino como a ABP, uma vez que, as atividades propostas ajudaram os docentes a saírem da rotina. Nos estudos de Câmara et al. (2020), a efetividade da ABP foi evidenciada para a elaboração de projetos formativos, considerando a resolução de problemas reais e autênticos relativos à formação continuada de professores:

[...] Por ser uma metodologia flexível, a ABP permitiu a utilização de diferentes técnicas, recursos e instrumentos importantes para que a estratégia utilizada para desenvolvê-la, no caso a oficina formativa, pudesse ser implementada com a colaboração/cooperação entre os participantes, de forma dinâmica. (p. 18).

A metodologia da ABP também foi discutida por Leal e colaboradores (2018, p. 124) "é uma metodologia ativa e diversa da tradicional, o discente ao buscar respostas para os questionamentos propostos nessa metodologia, sente-se mais motivado ao entender que é artífice de seu conhecimento". Argumentam também que o professor precisa abrir mão do papel de condutor desse processo, delegando o protagonismo aos estudantes.

\section{PROCEDIMENTOS METODOLÓGICOS}

Para o desenvolvimento deste trabalho, foi utilizada a abordagem metodológica qualitativa do tipo exploratória, através da observação participante. Nessa, o pesquisador se torna parte da situação observada, interagindo por longos períodos com os sujeitos, buscando partilhar o seu cotidiano para sentir o que significa estar naquela situação. O observador participante combina a observação com entrevistas e análise de documentos (ALVESMAZZOTTI, 1999).

A maior parte das pesquisas qualitativas se propõe a preencher lacunas no conhecimento, sendo poucas as que se originam no plano teórico, logo são definidas como descritivas ou exploratórias. As lacunas relacionam-se à compreensão de processos que ocorrem em uma dada instituição, grupo ou comunidade (ALVES-MAZZOTTI, 1999). 
O estudo foi realizado com 16 discentes do curso de Licenciatura em Ciências Naturais de uma universidade pública Federal localizada na região Norte do país, durante uma disciplina do curso. Nesta trabalhou-se com a ABP, assim durante a fase teórica, foram abordados aspectos gerais sobre a utilização da metodologia e foi apresentado o tema geral proposto: "Ecologia Terrestre".

A partir do tema geral, os alunos ficaram livres para desenvolverem a questão problema e as hipóteses com as quais pretendiam trabalhar. Dessa forma, os projetos foram desenvolvidos em sala de aula e a execução foi realizada em uma fazenda experimental da Universidade. Os discentes organizaram-se em cinco equipes denominadas E1, E2, E3, E4 e E5 e ficaram livres para escolherem os tópicos mais significativos e motivadores para eles próprios, a partir do tema geral proposto. Cada discente dentro do grupo foi referido neste artigo pelo código DxEy, no qual x e y são números que representam e diferem cada um. Por exemplo: D1E1 é o discente 1 da equipe 1 e assim sucessivamente.

Para a realização deste trabalho, foram utilizados os seguintes instrumentos: a) roteiro de entrevista e grupo focal. Para análise dos dados, trabalhamos com a Análise Textual Discursiva (ATD) de Moraes e Galiazzi (2013). A análise Textual discursiva é uma técnica que visa buscar nas falas as unidades de significado que serão classificadas em categorias. Para o desenvolvimento do presente trabalho foi utilizado o método misto, no qual os dois métodos dedutivo e indutivo foram combinados num processo de análise misto pelo qual partimos de categorias definidas a priori com base nas teorias de estudo da pesquisa e após a análise do corpus, por indução, foram desenvolvidas as categorias emergentes. Portanto, as categorias e subcategorias foram criadas para o processo de alocação das unidades de análise dos dados da entrevista e grupo focal.

Portanto, as categorias e subcategorias foram criadas para o processo de alocação das unidades de análise dos dados da entrevista e grupo focal. No quadro 01, é possível observar as categorias e as respectivas subcategorias desenvolvidas, além das questões relacionadas do roteiro de entrevista.

Quadro 1 - categorias, subcategorias e questões do roteiro de entrevista.

Categoria A: ABP para estimular o
desenvolvimento do espírito científico a partir de
questões-problemas

Questões

questões-problemas 


\begin{tabular}{|c|c|}
\hline $\begin{array}{c}\text { Subcategoria A.1 } \\
\text { O processo de gênese do projeto }\end{array}$ & $\begin{array}{c}\text { Q1-Como foi para } \\
\text { desenvolver a questão do projeto? }\end{array}$ \\
\hline $\begin{array}{l}\text { Subcategoria A.2 } \\
\text { Dificuldades para desenvolver a questão- } \\
\text { problema do projeto }\end{array}$ & $\begin{array}{l}\text { Q2-Você considera a fase de } \\
\text { elaboração da questão a mais } \\
\text { complicada? }\end{array}$ \\
\hline $\begin{array}{c}\text { Categoria B: A ressignificação do erro a partir } \\
\text { da ABP }\end{array}$ & Questões \\
\hline $\begin{array}{c}\text { Subcategoria B.1 } \\
\text { Retificações do projeto }\end{array}$ & $\begin{array}{l}\text { Q3- As correções foram } \\
\text { importantes para seu aprendizado? }\end{array}$ \\
\hline $\begin{array}{c}\text { Subcategoria B.2 } \\
\text { Dificuldades no campo }\end{array}$ & $\begin{array}{l}\text { Q4-Sentiu dificuldade para } \\
\text { executar o projeto em campo? }\end{array}$ \\
\hline $\begin{array}{l}\text { Subcategoria B.3 } \\
\text { O reconhecimento do erro como propulsor do } \\
\text { desenvolvimento do conhecimento. }\end{array}$ & $\begin{array}{c}\text { Q5-Você acha que a ciência se } \\
\text { constrói mais baseada em erros ou } \\
\text { acertos? }\end{array}$ \\
\hline
\end{tabular}

Fonte: Organizado pelos autores

Trabalhamos também com a abordagem, grupo focal, que segundo Powell e Single (1996, p.449) "é um conjunto de pessoas reunidas por pesquisadores para discutir e comentar um tema, que é o objeto de pesquisa, a partir de sua experiência pessoal" e para conduzir o grupo focal é necessário o facilitador ou moderador do processo ter cuidado para que a comunicação se desenvolva sem ingerências indevidas da parte dele (GATTI, 2005). A técnica é utilizada quando há interesse em compreender ideias, sentimentos, representações, valores, comportamentos, bem com compreender os porquês de determinados posicionamentos (GATTI, 2005).

Portanto, para o trabalho com o grupo focal o roteiro ficou assim estabelecido: após a defesa dos projetos em campo os membros das equipes reuniram-se em círculo e foi realizada uma única questão direcionada a todos os presentes. Na ocasião, os discentes ficaram a vontade para expressar e dialogar expondo suas argumentações sobre a atividade realizada e o questionamento levantado. Em nenhum momento foram realizadas interferências que comprometessem as argumentações dos discentes. Para análise do grupo focal foi desenvolvida a Categoria C: o medo de cometer erro como obstáculo ao desenvolvimento do espírito científico na formação do professor de ciências. A questão trabalhada foi: gostaria de saber de vocês o que aprenderam com esta atividade. 


\section{ANÁLISE E DISCUSSÃO DOS RESULTADOS}

As unidades de significado identificadas nas falas dos alunos foram alocadas em cada categoria e subcategoria desenvolvida. A seguir, seguem as subcategorias e suas correlações: A.1, representa as falas sobre o desenvolvimento da questão problema do projeto, a A.2, representa as dificuldades apresentadas para desenvolver a questão do projeto, a B.1, aborda as retificações realizadas e sua relevância, a B.2, representa as dificuldades de execução no campo e a B.3 reflete a importância do erro no processo de desenvolvimento do espírito científico.

Logo, para a subcategoria A.1, evidenciamos nas falas dos 16 alunos, unidades de significado, que representam a questão problema do projeto, desenvolvida em função do que os alunos consideravam significativo e interessante para eles, como podemos observar nas falas:

a gente começou a colocar (sic) as nossas ideias o que achávamos interessante (D1E1 para Q1, grifo nosso);

boa parte do grupo gosta mais da área de botânica, então todo mundo já foi com o olhar voltado para fazer uma coisa com planta especificamente (D1E2 para Q1, grifo nosso);

as meninas queriam que a gente trabalhasse com minhocas, mas eu particularmente sou apaixonada por samambaia, então tipo foi uma ideia apenas que eu dei e a gente apresentou a ideia para o professor (D3E1 para Q1, grifo nosso).

Analisamos que os alunos desenvolveram a questão problema em função do que consideravam significativo e essa é uma das características da ABP: “a questão fornece a tarefa geral ou a meta declarada para o projeto e deve ser motivadora e significativa para os discentes" (BENDER, 2015, p. 17).

Fonseca (2008), ao discutir a pedagogia proposta por Bachelard, nos diz que “[...] A nova pedagogia científica pensada por Bachelard é essencialmente crítica e estimula professores e alunos a exercitarem o pensamento aberto e a capacidade de formular questõesproblemas" (p. 366). O ato de fazer questionamentos e não aceitar problemas prontos e correr atrás para desenvolvê-los são pontos essenciais para o crescimento e desenvolvimento intelectual do aluno. Salientamos aqui a relevância das discussões persistentes trazidas por 
Bachelard quando diz que o sentido de questionar e problematizar é que caracteriza o espírito científico.

Para a Subcategoria A.2 em torno de $93 \%$ das falas apresentaram unidades de significado que representam a questão problema como a mais complicada para desenvolver no projeto. Em $7 \%$ não foram identificadas unidades para esta discussão. Logo, podemos observar evidências da questão problema ser a mais complicada, nos seguintes exemplos:

\begin{abstract}
a gente colocou a pergunta, mas nem sabia fazer a pergunta porque apesar de ser simples a gente não conseguia formar ali porque a gente achava que a pergunta era hipótese, a gente já estava colocando a resposta sem ter testado (D2E1 para Q2, grifo nosso);
\end{abstract}

pensar em como fazer uma questão foi bem complicado (D2E5 para Q2, grifo nosso);

a gente não tinha a ideia, essa foi a maior dificuldade (D1E5 para Q2, grifo nosso).

Os alunos relatam que pensar em desenvolver uma questão é algo complicado e a dúvida entre questão problema e hipótese ficou evidenciada. Pérez (2001, p.26) expõe que "formular um problema não constitui tarefa fácil. Todavia, não há como deixar de reconhecer que o treinamento desempenha papel fundamental nesse processo".

Prosseguindo com as discussões, na subcategoria B.1, foram alocadas as unidades de significado referente a retificação. Em torno de 50\% das falas foram identificadas, unidades que representam a relevância da retificação para o aprendizado. Como, por exemplo:

sim, porque eu consegui diferenciar a questão das hipóteses (D2E4 para Q3, grifo nosso);

as correções elas foram importantes... o erro é muito importante porque você só aprende quando erra (D1E5 para Q3, grifo nosso);

sim, porque em relação a essas questões que a gente teve que corrigir a gente viu o problema que a gente tava tendo e através desse problema a gente conseguiu chegar num resultado (D2E2 para Q3, grifo nosso).

O conhecimento gerado a partir das retificações foi evidenciado. Podemos observar, a superação da dificuldade em relação ao significado entre questão e hipótese, além do destaque conferido ao erro no processo de desenvolvimento do conhecimento. Diante desse contexto, estabelecemos diálogo com o seguinte raciocínio: "a perspectiva de erros retificados caracteriza o espírito científico" (BACHELARD, 1996, p. 14). Em torno de 43\% das falas não foram identificadas unidades de significado para a discussão e em aproximadamente $7 \%$ foi evidenciado que a retificação não foi realizada.

Recebido em: $25 / 11 / 2020$

Aceite em: 28/07/2021 
Percebemos que o fator motivação foi determinante e faz parte do papel da ABP oportunizar esse engajamento. De acordo com Bender (2015), a ABP é eficaz em envolver os estudantes em investigações que ultrapassam os limites da sala de aula e que, além da aprendizagem acadêmica, proporcionam motivação.

No trabalho de Garcês et al. (2018), a função da ABP como promotora da motivação nos alunos em processo de formação também foi evidenciada: “[...] A ABP possui muitas vantagens em relação ao ensino tradicional, entre elas: a maior participação dos alunos nas atividades e o aumento na motivação dos estudantes" (p. 530).

Na subcategoria B.3 evidenciamos em 100\% das falas, unidades de significado, a consciência do erro e sua relevância para o desenvolvimento do conhecimento, como podemos observar nos exemplos:

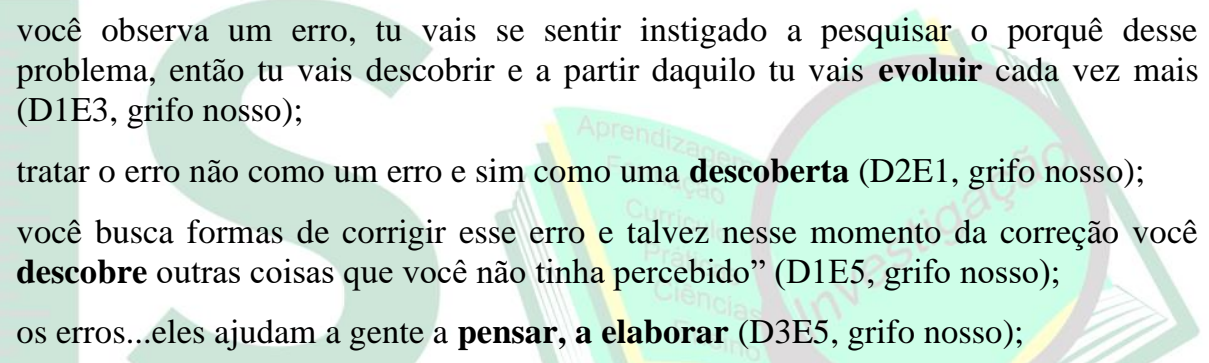
problema, então tu vais descobrir e a partir daquilo tu vais evoluir cada vez mais (D1E3, grifo nosso); tratar o erro não como um erro e sim como uma descoberta (D2E1, grifo nosso); você busca formas de corrigir esse erro e talvez nesse momento da correção você descobre outras coisas que você não tinha percebido" (D1E5, grifo nosso); os erros...eles ajudam a gente a pensar, a elaborar (D3E5, grifo nosso);

O ponto central do resultado exposto foi a percepção dos alunos acerca da visão crítica da Ciência, promovendo a ruptura do entendimento inadequado de Ciência irrefutável. O erro é citado como uma possibilidade de aprendizado sendo ressignificado no contexto do processo de ensino e aprendizagem.

Nota-se discussões em torno da aprendizagem em função dos erros nos trabalhos de Allchin (2012) que enfatiza o papel do erro no processo de geração do conhecimento relatando que se o objetivo da atividade didática é ensinar como a Ciência funciona, portanto é igualmente importante ensinar para os educandos como a Ciência não funciona. No trabalho de Pessim e Leite (2020) foi discutido que a identificação dos erros dos alunos é importante bem como intervir no erro para que o aluno alcance a aprendizagem. Com tal característica, o trabalho de Santos Júnior e Barboza (2020) discute a importância de compreender as causas e as motivações do erro dos alunos.

Bender (2015, p. 12) reforça que "a Aprendizagem Baseada em Projetos já é vista por muitos como a melhor abordagem para enfatizar as habilidades de resolução de problemas em 
um mundo onde o conhecimento se torna obsoleto no momento em que é impresso". Essa compreensão nos faz estabelecer relações com o pensamento de Bachelard frente ao novo espírito científico, baseado nos descontinuísmos, nas discussões e reflexões constantes e na ideia de que o conhecimento é construído a partir de verdades provisórias.

Passamos agora para a análise do grupo focal analisando as unidades de significado alocadas na categoria $\mathrm{C}$, o medo de cometer erro como obstáculo na formação do professor de Ciências. Em torno de $40 \%$ das falas apresentaram unidades de significado que representam a discussão supracitada, por exemplo:

acho que a parte mais difícil foi a gente entrar num consenso do que a gente ia fazer construímos várias hipóteses, mas a gente desconstruiu porque a gente ficava com medo de trazer isso e fosse uma coisa que não fosse possível (D1E4, roda de conversa, grifo nosso);

o medo de errar sempre e esquecer acontecem mesmo e nas escolas no ensino de Ciências isso é natural porque a atenção está voltada toda para o método como é que se faz e não para como a ideia foi construída (D2E2, roda de conversa, grifo nosso);

realmente o medo de errar nos persegue, então a partir desta experiência eu pude abrir mais a minha mente para as coisas que tem ao meu redor e agora eu procuro buscar mais e vou tentar não ficar presa somente a sala de aula (D3E5, roda de conversa, grifo nosso).

Existem diversos entendimentos sobre o erro, mas ainda prevalecem aqueles que o relacionam a algo negativo, que deve ser evitado ou escondido. Na fala do D1E4 mostra-se claramente a questão de tentar evitar ao máximo o erro e, em tal caso, ideias foram desconstruídas por conta do medo de que não saísse tudo dentro dos padrões. Quanto a isso, corroboramos com o seguinte pensamento de Zytkuewisz e Bego (2018, p. 76) que relatam: “a preocupação com a eliminação de possíveis erros que podem ocorrer em atividades experimentais é quase obsessiva, como se esse fosse algo alheio e distante do processo científico de construção do conhecimento".

O medo de errar não contribui para o desenvolvimento do espírito científico, pois o aluno deixa de se tornar crítico e reflexivo diante das situações impostas, neste ponto citamos Gil Perez, (2001) que argumenta que a criação de uma rotina "correta", pode imprimir uma visão de certeza da natureza da atividade científica na mente do aluno, quando na verdade pode falhar. Embora este estudo não seja recente, essa visão ainda prevalece como podemos observar no presente estudo. 
Na fala do D2E2, percebe-se a reflexão em torno do medo de errar que vai ao encontro do pensamento de Bachelard sobre considerar os caminhos, impasses e avanços na produção de conhecimento. Coloca-se em evidência o processo de desenvolvimento de ideias, adotando uma postura que difere da concepção de Ciência infalível.

Souza et al. (2013) expõem que [...] "no ambiente escolar, a predominância da ideia de erro como algo contraproducente, a ser penitenciado e constrangido, permeia o processo avaliativo, desqualificando o aluno e condenando-o, muitas vezes, como o único responsável pela sua não aprendizagem, pelo seu insucesso" (p. 3). Esse entendimento ainda perdura visto que para muitos docentes, discutir sobre o erro não faz parte do processo de aprendizagem (SILVA, 2019).

A consequência é a efetivação de "práticas corretivas autoritárias, com implicações na autoestima do aluno, ao estimular sentimento de rejeição, medo, fracasso e incapacidade para aprender" (PINTO, 1998, p. 98). Ressaltamos a ausência de trabalhos recentes que abordam especificamente o medo de errar aliado a metodologia ativa, $\mathrm{ABP}$, porém identificamos que a ideia negativa do erro ainda permanece e é discutida em trabalhos recentes dentre eles Damasceno Júnior (2020); Miranda et al. (2018) e Pessim e Leite (2020) citados anteriormente.

O D3E5, expressa o medo de errar e tece considerações positivas sobre a atividade realizada e reafirma $o$ interesse em não ficar atrelado somente à sala de aula após a sua formação. Evidenciamos também que a atividade com projetos estimulou os alunos, colaborando para a superação do medo em relação a desenvolver projetos:

\footnotetext{
eu sentia muito medo e dificuldade com projetos, então me ajudou a começar a pensar e perder um pouco do meu medo (D2E5, grifo nosso);

eu não sabia realmente o potencial que tinha isso e hoje em dia eu já me questiono: como eu faria a pesquisa? Como que se pode fazer a pesquisa? (D1E1);

Eu já quebrei esse medo que eu tinha ...eu tinha até medo de pesquisar como se fazia uma pesquisa (D3E2, grifo nosso).
}

A partir das falas, percebe-se que a ABP abriu oportunidades para se pensar sobre o erro oportunizando um processo dialético. Mostrando-se hábil para possibilitar discussões sobre as dificuldades atreladas ao medo, pois os alunos questionaram, relatando que perderam o medo que tinham após a atividade realizada. 


\section{CONCLUSÃO}

Os resultados apresentados mostram a necessidade de agir no tocante a formação do espírito científico dos futuros professores da Educação Básica, a partir, por exemplo, da inserção de metodologias ativas, como a metodologia da Aprendizagem Baseada em Projetos, que oportuniza aos alunos meios pelos quais eles podem instigar o pensamento, por meio do exercício de questões problemas.

Como vimos a partir da experiência didática promovida pela $\mathrm{ABP}$, os erros foram ressignificados e transformados em uma situação pedagógica privilegiada inseridos num contexto significativo para a aprendizagem. A partir das discussões advindas de Bachelard foi possível analisar as falas e extrair as unidades de significado que apresentaram a relevância do erro e da retificação e o resultado central evidenciado que foi o medo de errar.

As conclusões e implicações da pesquisa para a área de Educação em Ciências e Matemática recaem sobre a importância da utilização da $\mathrm{ABP}$ na formação inicial de professores de Ciências para instigar o desenvolvimento de questões problemas que são essenciais para a formação do espírito científico, além de estimular os alunos a tornaram-se críticos fazendo-os pensar na ciência e no papel do trabalho coletivo e cooperativo entre equipes.

Ressalta-se, por fim, que deixar de expor ideias não contribui para o desenvolvimento do espírito científico, pois o aluno deixa de se tornar crítico diante das situações impostas, logo o medo de errar torna-se um obstáculo ao desenvolvimento do espírito científico. Destaca-se ainda, que a ABP se mostrou como "experiência exigente" no viés de Bachelard abrindo oportunidades para se pensar sobre a relevância do erro no ensino e na aprendizagem.

\section{REFERÊNCIAS}

ANTUNES, Jeferson; NASCIMENTO. Verônica Salgueiro do; QUEIROZ, Zuleide Fernandes de. Metodologias ativas na educação: problemas, projetos e cooperação na realidade educativa. Informática na Educação: teoria \& prática, Porto Alegre, v. 22, n. 1, p. 111-127, jan./abr. 2019. 
ALLCHIN, Douglas. Teaching the nature of science through scientific errors. Science Education, v.96, n.5, p. 904-926, 2012.

ALVES-MAZZOTTI, Alca Judith; GEWANDSZNAJDER, Fernando. O método nas ciências naturais e sociais: pesquisa quantitativa e qualitativa. 2 ed. Cap. 6. São Paulo: Pioneira, 1999.

ARAGÃO, Milena; FREITAS, Anamaria Gonçalves Bueno de. Práticas dos castigos escolares: enlaces históricos entre normas e cotidiano. Conjectura, v. 17, n. 2, p. 17-36, maio/ago. 2012.

BACHELARD, Gaston. A Formação do espírito científico: contribuição para uma psicanálise do conhecimento. Trad. Estela dos Santos Abreu. 4 ed. - Rio de Janeiro: Contraponto, 2003.

BARBOSA, Elyana; BULCÃO, Marly. Bachelard: pedagogia da razão, pedagogia da imaginação. Petrópolis: Vozes, 2004.

BENDER, Willian. Aprendizagem baseada em projetos: educação diferenciada para o século XXI. Porto Alegre: Penso, 2015.

BRITO, Isabel Cristina Rodrigues de Lucena; VIEIRA, Eduardo Paiva de Pontes. Avaliação e pressupostos bachelardianos: tecendo relações para a formação docente em Ciências e Matemática. Amazônia | Rev. de Educ. em Ciências e Matemáticas. v.16, n. 36, 2020. p. 181-189. ISSN: 2317-5125.

CÂMARA, Aldemira de Araújo; RIBEIRO, Carmem Lúcia de Souza; AZEVEDO, Rosa Oliveira Marins; MENDONÇA, Andréa Pereira. Elaboração de projetos formativos por meio da metodologia da Aprendizagem Baseada em Projetos. Revista de Estudos e Pesquisas sobre Ensino Tecnológico, v. 6, Edição Especial, 2020.

CARRIJO, Ana Regina Dalmaschio; MENDES, Ana Nery Furlan. Avaliação da aprendizagem e o erro construtivo no ensino de química. Experiências em Ensino de Ciências V.12, $\mathrm{N}^{\circ} 6,2017$.

FONSECA, Dirce Mendes da. A pedagogia científica de Bachelard: uma reflexão a favor da qualidade da prática e da pesquisa docente. Educação e Pesquisa, São Paulo, v.34, n.2, p. 361-370, maio/ago. 2008.

GATTI, Bernardete Angelina. Grupo focal na pesquisa em Ciências sociais e humanas. Brasília: Líber Livro, 2005.

GARCÊS, Bruno Pereira; SANTOS, Kelly de; OLIVEIRA, Carlos Alberto de. Aprendizagem Baseada em Projetos no Ensino de Bioquímica Metabólica. Revista IberoAmericana de Estudos em Educação, Araraquara, v. 13, n. esp 1, p. 527-534, maio 2018.

JAPIASSU, Hilton. Para ler Bachelard. Editora: Francisco Alves.Rio de Janeiro, (1976). 
DAMASCENO JÚNIOR, José Ademir. O papel do erro no processo de ensino e aprendizagem de ciências e matemática: contributos da neurociência. Revista Prática Docente. v. 5, n. 2, p. 1171-1190, mai/ago 2020.

LOPES, Alice Ribeiro Casimiro. Bachelard: O filósofo da desilusão. O caderno Brasileiro de Ensino de Física. v.13, n3: p.248-273, dez.1996.

LOVATO, Fabricio Luís; MICHELOTTI, Angela; LORETO, Elgion Lucio da Silva Loreto Metodologias ativas de aprendizagem: uma breve revisão. Acta Scientiae, v. 20, n. 2, p. 154$171,2018$.

LEAL, Edvalda Araújo; MIRANDA, Gilberto José; NOVA, Silvia Pereira de Castro Casa. Revolucionando a Sala de Aula: Como Envolver o Estudante Aplicando as Técnicas de Metodologias Ativas de Aprendizagem. Editora: Atlas; Edição: 1, 2018.

MORAES, Roque; GALIAZZI, Maria do Carmo. Análise Textual Discursiva. Editora: Unijuí. $2^{\text {a }}$ Ed. 2013.

MIRANDA, Weverton dos Santos; FARIAS, Luciana de Nazaré; FILHO, Silvio Carlos Ferreira Pereira. Aspectos epistemológicos subjacentes a erros individuais frequentes no ensino institucionalizado. Amazônia - Revista de Educação em Ciências e Matemáticas v.14 (30), Jan-Jul 2018.

PÉREZ, Daniel Gil; MONTORO, Isabel Fernández; ALÍS, Jaime Carrascosa; CACHAPUZ, António; PRAIA, João. Para uma imagem não deformada do trabalho científico. São Paulo, Ciência \& Educação, v. 7, n. 2, p. 125-153, 2001.

PINTO, Neuza Bertoni. O erro como estratégia didática no ensino da matemática. Tese (doutorado em didática)- Universidade de São Paulo. São Paulo, p. 320. 1998.

POWELL, Richard; SINGLE, Helen. Focus Groups. International Journal for Quality in Health Care, 8, 499-504. [2]. 1996.

PESSIM, Marcelo Orlando Sales; LEITE, Eliana Alves Pereira. A avaliação e o erro no processo de ensino-aprendizagem na formação inicial e continuada de professores de matemática. Revista Prática Docente. V. 5, N. 1, P. 5[3] 44-562, Jan/Abr 2020.

SOUZA, Nadia Aparecida de; SIBILA, Miriam Cristina Cavenaghi; CORREIA, Larissa Costa. Do erro como fracasso ao erro como possibilidade de superação de dificuldades.

Imagens da Educação, v. 3, n. 3, p. 51-61, 2013.

SANTOS DE SOUZA, Denise.; SANTOS DE SOUZA DA SILVA, Cristine.; BEDIN, Everton. A relevância da observação na formação inicial docente com vistas no desenvolvimento da prática reflexiva. Revista Insignare Scientia - RIS, v. 3, n. 1, p. 322 339, 4 jun. 2020.

Recebido em: 25/11/2020

Aceite em: 28/07/2021 
SANTOS JÚNIOR, José Ferreira dos; BARBOZA, Pedro Lucio. Como o professor de Matemática percebe o erro do aluno resolvendo atividades matemáticas. Research, Society and Development, v. 9, n. 8, e246985290, 2020.

SILVA, Luciano Pontes da. Um estudo da atenção seletiva na aprendizagem das funções trigonométricas: etiologias e tipologias de erros na perspectiva da neurociência cognitiva. 2019. 209f. São Cristóvão: Dissertação (Mestrado em Ensino de Ciências Naturais e matemática). Programa de Pós-Graduação em Ensino de Ciências Naturais e Matemática Universidade Federal de Sergipe, São Cristóvão, 2019.

SUÁREZ SILVA, J.; FORTES BRAIDANTE, M. Aprendizagem significativa: concepções na formação inicial de professores de Ciências. Revista Insignare Scientia - RIS, v. 1, n. 1, 18 jun. 2018.

SIQUEIRA, Vanessa Fagundes; GOI, Mara Elisangela Jappe. Formação de professores: resolução de problemas no ensino de Ciências da Natureza. Revista conexão UEPG, Ponta Grossa, Paraná. V. 16, 2020.

ZYTKUEWISZ, Matheus; BEGO, Amadeu. Crítica à experimentação tradicional e a importância do erro no processo de Ensino e Aprendizagem de Ciências. Revista Iluminar. ISSN 1984-8625. Dezembro de 2018. 